\title{
EL GÉNERO MUELLERA L. f. EN MESOAMÉRICA Y NORTE DE SUDAMÉRICA
}

\author{
Mario Sousa S. ${ }^{1}$ y Solange Sotuyo \\ Universidad Nacional Autónoma de México, \\ Instituto de Biología, Apdo. postal 70-367, \\ 04510 México, D.F., México. \\ 1Autor para la correspondencia: sousa@unam.mx
}

\begin{abstract}
RESUMEN
Se realizó un análisis filogenético preliminar, con secuencias de los espaciadores internos transcritos del rDNA (nrITS) nrITS, apoyando la ubicación de Muellera como entidad monofilética, hermana del género Dahlstedtia, siendo ambos grupos hermanos de Lonchocarpus. Se estudiaron 13 especies de Muellera de Mesoamérica y norte de Sudamérica; se hacen tres cambios nomenclaturales de Lonchocarpus a Muellera; se describen tres especies nuevas para la ciencia: Muellera amazonica, M. burkartii y M. chocoensis. Además se describen e ilustran a M. frutescens, M. tubicalyx y M. unifoliolata y se presenta una clave dicotómica para contrastar las diferencias entre los componentes reconocidos del género.
\end{abstract}

Palabras clave: Leguminosae, Lonchocarpus, Mesoamérica, Muellera, norte de Sudamérica, sistemática molecular.

\begin{abstract}
A preliminary phylogenetic analysis with nuclear ribosomal internal transcriber spacers (nrITS) sequence supports Muellera as a monophyletic group, sister of the genus Dahlstedtia, both groups sisters of Lonchocarpus. Thirteen species of Muellera from Mesoamerica and north of South America were studied. The nomenclature of Lonchocarpus to Muellera underwent three changes. Three new species are described to science: Muellera amazonica, M. burkartii and M. chocoensis. M. frutescens, M. tubicalyx and M. unifoliolata are also described and illustrated. A dichotomous key is presented to compare the differences between species.
\end{abstract}


Key words: Leguminosae, Lonchocarpus, Mesoamerica, Muellera, North of South America, molecular systematic.

Muellera fue creado por C. von Linné f. (1781 [1782]) y Burkart $(1952,1969)$ lo caracterizó diferenciándolo de Lonchocarpus por su "fruto toruloso con pericarpio grueso y por las anteras elípticas-apiculadas, con algunos pelos"; Sousa y Peña de Sousa (1981) y Sousa (1993, 2005 y 2009) han apoyado su reconocimiento como género aparte de Lonchocarpus y caracterizado morfológicamente.

Geesink (1984) consideró a Muellera como un grupo de (3 a 4) especies perteneciente al género Lonchocarpus sect. Punctati Benth.; opinión que han compartido en parte Teixeira et al. (2000) y Silva y Tozzi (2008), principalmente en función de la presencia o ausencia de glándulas translúcido punteadas en sus folíolos. Por otro lado, recientemente Silva et al. (2010) incluyeron sólo a las especies sin glándulas translúcidas de la sect. Laxiflori Benth., la cual creó Bentham (1860) como un grupo de Lonchocarpus; a la vez Bentham reconoció a Muellera como género aparte y lo distinguió por su legumbre moniliforme. Bentham incluyó a dos especies, $M$. moniliformis L.f. [M. frutescens (Aubl.) Standl.] y M. mexicana (Zuccarini) Benth., esta última basada en Cyanobotrys mexicana Zuccarini, género y especie propuesto con elementos heterogéneos, de los cuales Sousa (2009) designó el material con hojas, inflorescencia y flores para lectotopificar el nombre y lo ubicó en sinonimia de una especie de Lonchocarpus [L. longistylus Pittier]. (El binomio L. mexicanus corresponde a una planta distinta). Silva et al. (2010) definen la sect. Punctati Benth. en forma diferente y más estrecha incluyendo al grupo alrededor de Lonchocarpus subglaucescens Mart. ex Benth. cuyos componentes poseen glándulas tanslúcido punteadas en sus hojas; a su vez a las especies sin tales glándulas las ubican en la sección Laxiflori. En la disposición que aquí se propone se reúnen en Muellera los árboles o arbustos con arreglo dístico sólo en los brotes jóvenes y helicoidal en las ramas leñosas, las flores en panícula, incluyendo a plantas de hojas punteadas y epunteadas, que en nuestro trabajo forman un clado con el género Dahlstedtia (véase Fig. 7). Por otro lado Sousa (2009) circunscribió a la sect. Punctati Benth. alrededor de Lonchocarpus violaceus Benth. [L. punctatus Kunth], que se caracteriza por sus hojas con arreglo marcadamente dístico, tanto en los brotes jóvenes como en las ramas ya con leño, glándulas punteado a lineolado translúcidas en sus foliolos y flores; bractéolas frecuentemente escariosas, distantes a la base del cáliz; flores en unidades bifloras; estandarte cuya lámina presenta aurículas y abaxialmente callos. Esta sección comprende alrededor de 27 especies. 
Muellera L. f., nom. cons.

Suppl. Pl.: 53, 329. 1781 [1782]. Especie tipo: Muellera moniliformis L. f. [= M. frutescens (Aubl.) Standl. (Coublandia frutescens Aubl.)].

Arbustos a árboles; corteza interior sin fluido resinoso al corte; tallos sólidos, con frecuencia en brotes cortos y largos, los cortos frecuentemente cicatricosos. Hojas con arreglo dístico más marcadamente en los brotes cortos; estípulas frecuentemente orbiculares a oblatas y cubriendo las yemas folíferas, pero también triangulares, sin cubrir completamente a las yemas en ocasiones pequeñas e inconspicuas; hojas imparipinnadas, con los folíolos opuestos, rara vez unifolioladas, los foliolos sin estipelas, frecuentemente glabros en el haz o algo pelosos y regularmente papilosos en el envés y bicolores, punteados o epunteados. Inflorescencias axilares, simples, paucifloras y laxas; pedúnculos florales generalmente ausentes, las flores pediceladas geminadas sobre el raquis floral primario; bractéolas lineares a oblongas, opuestas a alternas, distantes a cercanas al cáliz (aparentemente ausentes en $M$. lutea); cáliz algo giboso en la base vexilar, brevidentado, en ocasiones con el diente carinal más largo que los otros y cubriendo el ápice del botón; corola lila a violeta o en ocasiones amarilla, punteada o epunteada; lámina del estandarte cuneiforme en la base resolviéndose en la uña, cara abaxial sin aurículas, generalmente sin callos, pero frecuentemente con un canalículo vertical bordeado por dos pliegues que van del centro o de la base de la lámina, prolongándose en la uña; tubo estaminal generalmente libre en la base y formando dos fenestras (seudomonadelfo), sin callosidades en los bordes o en ocasiones diadelfo, las anteras uniformes, con frecuencia con pelosidad canescente pilósula sobre el conectivo y ápice del filamento; estilo g1abro; estigma terminal capitado. Legumbres indehiscentes, generalmente aplanadas, elípticas a oblongas, en ocasiones cortamente falcadas y rara vez moniliformes; semillas reniformes, con la testa lisa o en ocasiones crasa, aplanadas a esféricas a cilíndricas, con la testa quebradiza que se arruga (al secarse), el hilo lateral. Plántulas (sólo conocidas en Muellera frutescens y M. unifoliolata) con los cotiledones hipogeos, crasos; eófilos 1-foliolados, opuestos.

1. Muellera amazonica M. Sousa, sp. nov. Tipo: Perú. Loreto, Río Samaría near mouth, 440' S, 79²8' W, 6 Aug. 1982. A. Gentry, F. Ayala, R. Vázquez y G. Crillo 38165 (holotipo: MO!; isotipos: F!, MEXU!, NY!, US!). Fig. 1.

Nombre común: anil da Beira (Brasil). 


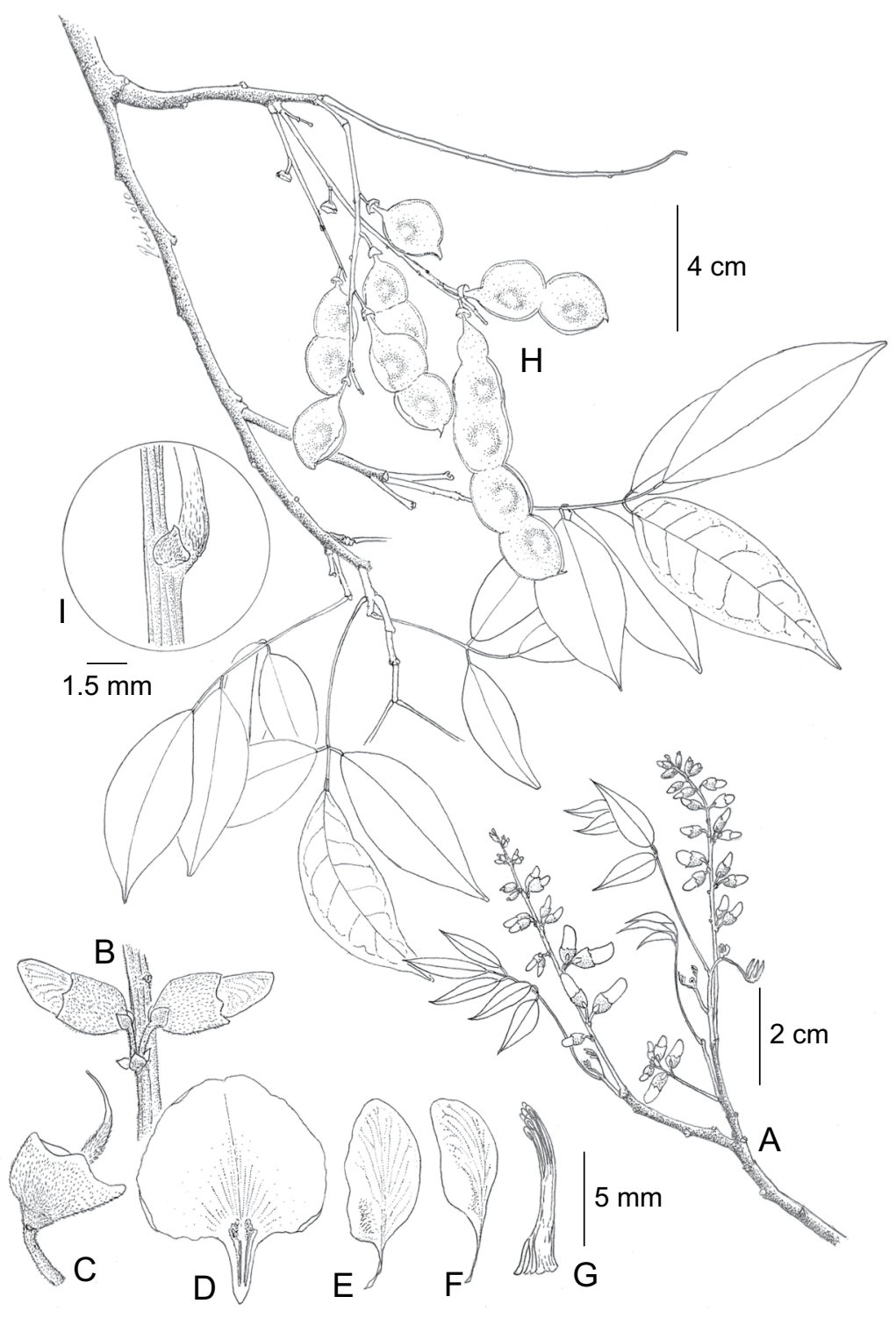

Fig. 1. Muellera amazonica M. Sousa. A. rama con hojas inmaduras e inflorescencias; B. unidad geminada, mostrando botones florales, bractéolas y brácteas florales; C. cáliz y gineceo; D. estandarte cara abaxial; E. ala; F. pétalo de la quilla; G. tubo estaminal; H. rama con hojas e infrutescencias; I. estípula. Rama con hojas inmaduras, inflorescencias, botones florales, cáliz y corola, tomados de A. Gentry et al. 38165 (F); tubo estaminal y estípula tomados de Graham y Schunke 491 (NY); ramas con hojas maduras e infrutescencias, tomados de Graham y Schunke 330 (NY). 
Arbor usque ad $20 \mathrm{~m}$ alta, caducifolia, rami moderate canescenti-sericei, postice glabri. Folia 5-foliolata, foliolis lanceolatis vel anguste lanceolatis, apice acuminato vel longe acuminato, supra glabris, translucido-punctatis, nervis lateralibus $11-13$ paribus. Inflorescentiae $4.5-11 \mathrm{~cm}$ longae, pedunculi florales admodum deminuti usque ad $1 \mathrm{~mm}$ longi, robusti, pedicelli geminati $2.5-4.5 \mathrm{~mm}$ longi, tenues, bracteolae 1-2.1 mm longae, ovatae vel ligulatae, calyx moderate canescenti-sericeus fundo atropurpureo; vexillum 9-10 mm latum, cuneiforme basi in ungue resolvens; ovarium (8)9-ovulatum. Legumen ellipticum vel oblongum, fere glabrum, coriaceum, margine vexillari 2-nervato per totam longitudinem anguste sulcato.

Árboles 6-13(-20) m de alto, caducifolios; ramas moderadamente canescente seríceas, posteriormente glabras. Estípulas ca. $1 \mathrm{~mm}$ de largo, ovadas, canescentes seríceas, cubriendo parcialmente las yemas folíferas, pronto caducas; pecíolo 2.5-3.6 cm de largo, acostillado con un canaliculo adaxial poco pronunciado. Hojas 5-folioladas, los folíolos 4.5-7 cm de largo, 1.7-2.2 cm de ancho, lanceolados a angostamente lanceolados, el ápice acuminado a largamente acuminado, el haz glabro, el envés esparcidamente canescente, papiloso, ligeramente bicolor, cartáceos a subcoriáceos, puberulentos, translúcido punteados, nervadura primaria y secundarias poco realzadas en el envés, nervaduras laterales 11-13 pares. Inflorescencias 4.5-11 $\mathrm{cm}$ de largo, simples, erectas, las flores moderadamente esparcidas en el raquis de la inflorescencia; pedunculadas, el pedúnculo 1-1.8 cm de largo; floración precoz; pedúnculos florales muy reducidos, hasta $1 \mathrm{~mm}$ de largo, robustos; pedicelos geminados 2.5-4.5 mm de largo, esbeltos; bractéolas 1-2.1 mm de largo, ovadas, liguladas y en ocasiones lineares, opuestas en la base del cáliz a distantes de él; cáliz 3.5-4 $\mathrm{mm}$ de largo, ligeramente giboso en la base vexilar, brevemente dentado, esparcida a moderadamente canescente seríceo con un fondo atropurpúreo; corola violeta, morada, azul, glabra, translúcido líneolada; lámina del estandarte 9-10 $\mathrm{mm}$ de ancho, cuneiforme en la base resolviéndose en la uña, con aurículas poco desarrolladas, sin callos, con un canal vertical bordeado por dos pliegues que se prolongan a la uña, la uña ca. $4.5 \mathrm{~mm}$ de largo; ovario (8)9-ovulado. Legumbre 3.6-8.5 cm de largo, 1.6$1.8 \mathrm{~cm}$ de ancho, elíptica cuando una semilla, oblongo constricta cuando 2 o más semillas, aplanada, indehiscente, glabra excepto esparcidamente canescente serícea en la base, opaca con moteado irregular pardo, coriácea, el estípite no bien definido, el margen vexilar 2-nervado con un angosto surco a todo lo largo, el margen carinal aquillado; semillas (solo inmaduras) 1-5, reniformes, con el hilo lateral, con la testa lisa de color claro. 
Distribución, hábitat, fenología: habita la cuenca alta del Río Amazonas, Colombia, Brasil y Perú, es de esperarse en Ecuador y Bolivia. En altitudes 90-150 m. La floración se presenta de finales de julio a finales de diciembre; la fructificación en noviembre.

Etimología. Esta especie es sólo conocida de la cuenca alta del Río Amazonas y el epíteto específico lo subraya.

Material adicional examinado: COLOMBIA: Amazonas: Loretuyacu River, Trapecio amazónico, R.E. Schultes 6723 (US). PERÚ: Loreto: margen R. Ucayali, Caño Iricahua, provincia Reguena, F. Encarnación 26484 (MO, NY, US). Maynas, comunidad de Pucallpa, M. Rimachi Y. 8883 (F, MO, NY, US). Uyacali: Coronel Portillo, orilla del Lago Yarinacucha, $8^{\circ} 21^{\prime} \mathrm{S}, 74^{\circ} 34^{\prime}$ 0, distrito Yarinacucha, $J$. Graham y J. Chunka Vigo 330 (MEXU, NY), 491 (NY). BRASIL: Amazonas: Rio Japurá, municipio Maraã, I.L. Amaral, C.A. Cid., J. Guedes y J. Lima 360 (MEXU). Pará: Rio Cuparí, Ingatubinha, entre Flexal e Sâo Raimundo, G.A. Black 47-2.141 (US).

2. Muellera broadwayi (Urb.) M. Sousa, comb. nov. Basónimo: Lonchocarpus broadwayi Urb., Symb. Antill. 5(3): 366. 1908. Tipo: Grenada. St. George. W.E. Broadway 1753 (lectotipo, aquí designado: NY!; isolectotipo: GH!).

Lonchocarpus sanctaemarthae Pittier, Contr. U.S. Natl. Herb. 20: 93. 1917. Tipo: Colombia. Cordillera de Santa Martha, near Mamatoca, H.H. Smith 107 (holotipo: US!; isotipos: A!, BR!, DUKE!, GH!, K!, MEXU!, NY!, TEX-LL!, VT!), syn. nov.

Muellera sanctaemarthae (Pittier) M.J.Silva et A.M.G. Azevedo, Taxon 61(1): 104. 2012. Syn. nov.

Lonchocarpus stenurus Pittier, Arb. Arbus. Venez. 6/8: 102. 1927. Tipo: Venezuela. Cerca de Barquisimato, bosque de macuto. J. Saer 139 (holotipo: US!), syn. nov.

3. Muellera burkartii M. Sousa, sp. nov. Tipo: Colombia. Cesar, between La Paz and Manaure, ca. km 5, $10^{\circ} 30^{\prime} \mathrm{N}, 72^{\circ} 55^{\prime} \mathrm{W}, 10$ Mar. 1993, A. Gentry y H. Cuadros 79181 (holotipo: MO!). Fig. 2.

Nombre común: macurutú (Colombia). 


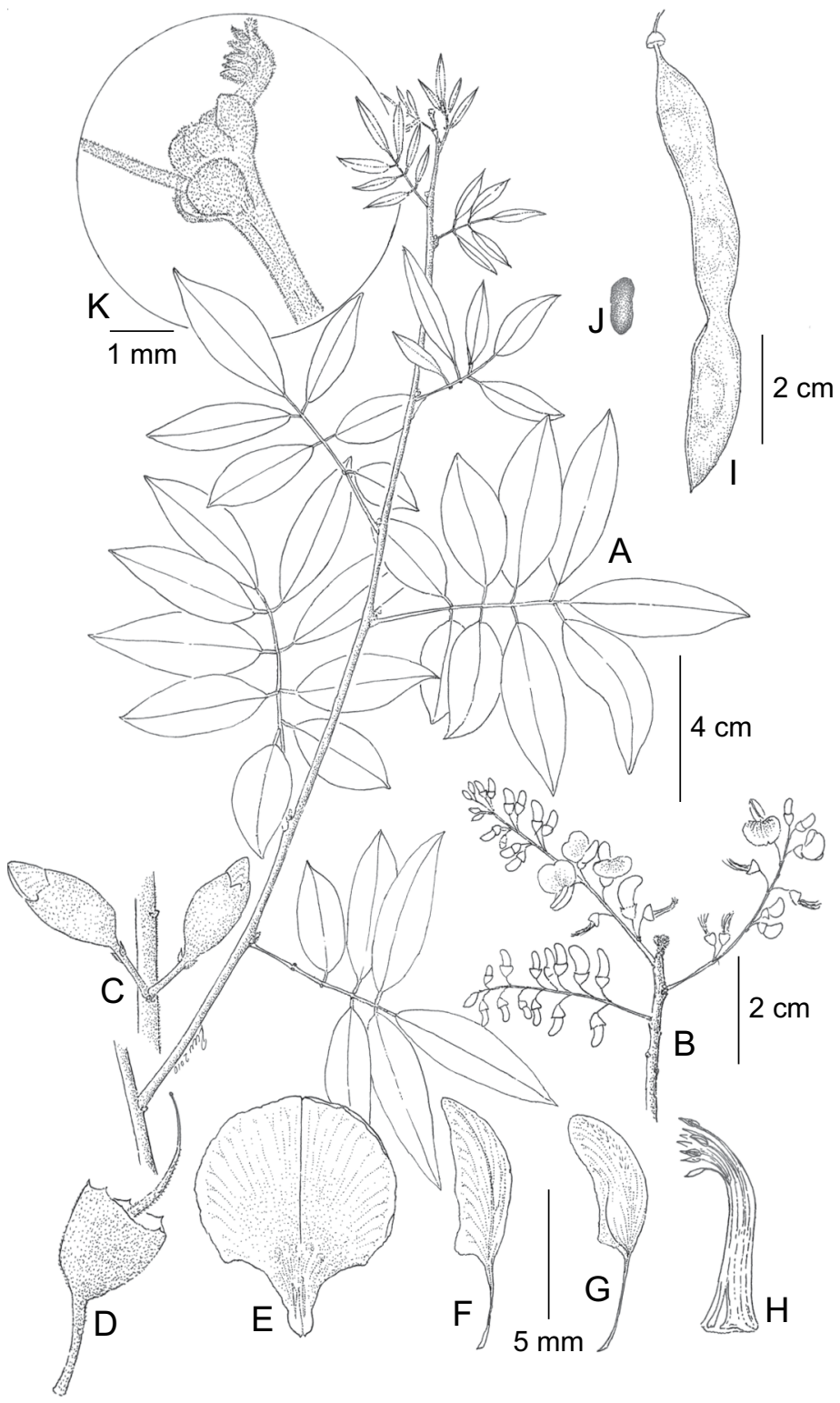

Fig. 2. Muellera burkartii M. Sousa. A. rama con hojas maduras; B. rama con inflorescencia aun sin hojas; C. unidad geminada, mostrando botones florales y bractéolas; D. cáliz y gineceo; E. estandarte, la cara abaxial; F. ala; G. pétalo de la quilla; H. tubo estaminal; I. legumbre; J. semilla; K. yema foliífera, mostrando las estípulas. Rama con hojas y yema foliífera, tomadas de Romero y Castañeda 8942 (MO); inflorescencia, flores, legumbre y semilla, tomadas de Dugand 5599 (US). 
Muellerae amazonicae M. Sousa affinis sed stipulis ca. $1.5 \mathrm{~mm}$ longis, oblatis, gemmas foliiferas omnino obtegentibus (vs. stipulis ca. $1 \mathrm{~mm}$ longis, ovatis, gemmas partim obtegentibus), petiolo 1.6-2.1 cm longo (vs. $2.5-3.6 \mathrm{~cm}$ longo), foliis (7-)9-foliolatis (vs. 5-foliolatis), foliolis 1.1-1.6 cm latis (vs. 1.7-2.2 cm latis), vexillo 7.5-8.5 mm lato (vs. 9-10 mm lato), ovario 6(7)-ovulato (vs. (8)9-ovulato), legumine 1-nervato, carinato, sine sulco (vs. margine vexillari 2-nervato per totam longitudinem anguste sulcato) differt.

Árboles 3-12 m de alto, caducifolios; ramas moderada a esparcidamente canescente seríceas, pronto glabras. Estípulas ca. $1.5 \mathrm{~mm}$ de largo, oblatas, cubriendo completamente a las yemas foliíferas, caducas; pecíolo $1.6-2.1 \mathrm{~cm} \mathrm{de}$ largo, terete, acostillado. Hojas (7-)9-folioladas, los folíolos 2.7-5 cm de largo, 1.1-1.6 cm de ancho, angostamente elípticos a lanceolados, el ápice acuminado, el haz glabrescente a glabro, el envés esparcidamente canescente puberulento, papiloso, ligeramente bicolor, cartáceos, translúcido punteados, nervadura primaria y secundarias poco realzadas en el envés, nervaduras laterales 11-12 pares. Inflorescencias 3.5-7 cm de largo, simples, erectas, las flores moderadamente esparcidas, cortamente pedunculadas, el pedúnculo $0.3-2 \mathrm{~cm}$ de largo; floración precoz en ocasiones coetánea; pedúnculos florales casi nulos; pedicelos 3.5-6.5 $\mathrm{mm}$ de largo, geminados, esbeltos, canescente seríceos; bracteólas 0.6-1 mm de largo, lanceoladas, liguladas, subopuestas a opuestas, lejanas o en la base del cáliz; cáliz 4-4.5 mm de largo, giboso en la base vexilar, brevemente dentado, moderadamente canescente seríceo con un fondo atropurpureo; corola morada, lila, magenta, translúcido líneolada; lámina del estandarte 7.5-8.5 mm de ancho, cuneiforme en la base resolviéndose en la uña, canescente serícea en el ápice adaxial, en la cara abaxial sin aurículas ni callos, con un canal vertical bordeado por dos pliegues que se prolongan a la uña, la uña 2-2.2 mm de largo; ovario 6(7)-ovulado. Legumbre ca. $8 \mathrm{~cm}$ de largo, 1-1.2 cm de ancho, oblongo-linear, indehiscente, aplanada, glabra, cartácea, algo constricta, el margen vexilar 1-nervado aquillado, sin surco, 0.7-0.8 mm de grosor, el margen carinal aquillado; semillas 4-5, 9-10.5 mm de largo, ca. $5 \mathrm{~mm}$ de ancho, $1.5 \mathrm{~mm}$ de grosor, oblongas; hilo lateral, testa lisa de color castaño.

Distribución, hábitat, fenología: especie endémica a Colombia, en la cuenca del Río Magdalena y el Cauca; habita mayormente en ciénegas y hay un reporte en áreas secas. En altitudes 20-350 m. La floración en febrero y marzo, con otro periodo en mayo; la fructificación con frutos maduros a mediados de febrero. 
Etimología. Se dedica esta especie al prominente botánico argentino Arturo Burkart (1906-1975), el cual ha sido uno de los más notables estudiosos de la sistemática de las leguminosas, tanto de Argentina como de toda Sudamérica; él fue de los primeros que $(1952,1969)$ reconoció a Muellera como género aparte de Lonchocarpus, caracterizándolo y reconociendo a dos especies.

Material adicional examinado: COLOMBIA: Bolívar: correjimiento La Raya, refugio El Paraíso, 3-4 km de Cuencas, sobre el río Cauca, $8^{\circ} 20^{\prime} \mathrm{N}, 74^{\circ} 30^{\prime} \mathrm{O}, R$. Callejas et al. 4340 (MO). Vía Carmen de Bolívar-Alto La Causona, H. Cuadros V. 1035 (MO). Magdalena: Ciénaga Santa Marta, carretera entre Don Juan y puente sobre el Toribio, R. Romero-Castañeda 8942 (MO). Valle del Río César, entre Vallito y Mata de Indio, $9^{\circ} 47^{\prime} \mathrm{N}, 73^{\circ} 40^{\prime} \mathrm{O}$, A. Dugand 5599 (US).

4. Muellera chocoensis M. Sousa, sp. nov. Tipo: Colombia. Chocó, area of Baudó, on bank of river Baudó, about $13 \mathrm{~km}$ upstream from estuary, at right bank of estuary of Quebrada Taporal, 4 Feb. 1967 H.P. Fucks \& L. Zanella 21720 (holotipo: MO!) Fig. 3.

Nombre común: barbasquillo (Colombia).

Usos: veneno para pescar (Colombia).

Muellerae frutescenti (Aubl.) Standl. affinis sed foliis 7-9-foliolatis (vs. 5-(-7)-foliolatis), foliolis (9.5-)11.5-15 cm longis (vs.5-12 cm longis), lanceolatis vel anguste ellipticis (vs. oblongis vel ovato-oblongis), nervis lateralibus 11-13 paribus (vs. 6-10 paribus), vexillo 10-12(-13.5) $\mathrm{mm}$ lato (vs. 5-9 $\mathrm{mm}$ ), ovario 7-ovulato (vs. 4-6-ovulato) differt.

Arbustos a árboles 1.5-6 m de alto; corteza interior sin fluido resinoso al corte; ramas pardo-amarillento seríceas, posteriormente glabrescentes. Estípulas ca. 3 $\mathrm{mm}$ de largo, ca. $3.2 \mathrm{~mm}$ de ancho, orbiculares a oblatas, pardo-amarillento seríceas, cubriendo las yemas foliíferas, caducas; pecíolo $4-5.5 \mathrm{~cm}$ de largo, con un canalículo adaxial a todo lo largo. Hojas 7-9-folioladas, los folíolos (9.5-)11.5-15 cm de largo, 3.5-4.5(-5.5) cm de ancho, lanceolados a angostamente elípticos, el ápice acuminado a largamente acuminado, el haz glabrescente, el envés canescente seríceo y densamente papiloso, marcadamente bicolores, membranáceos (en folíolos inmaduros) a cartáceas, diminutamente pelúcido punteados, nervadura primaria y secundarias muy poco realzadas en el envés, nervaduras laterales 11-13 pares. Inflorescencia 4.5-7.5(-9.5) cm de 


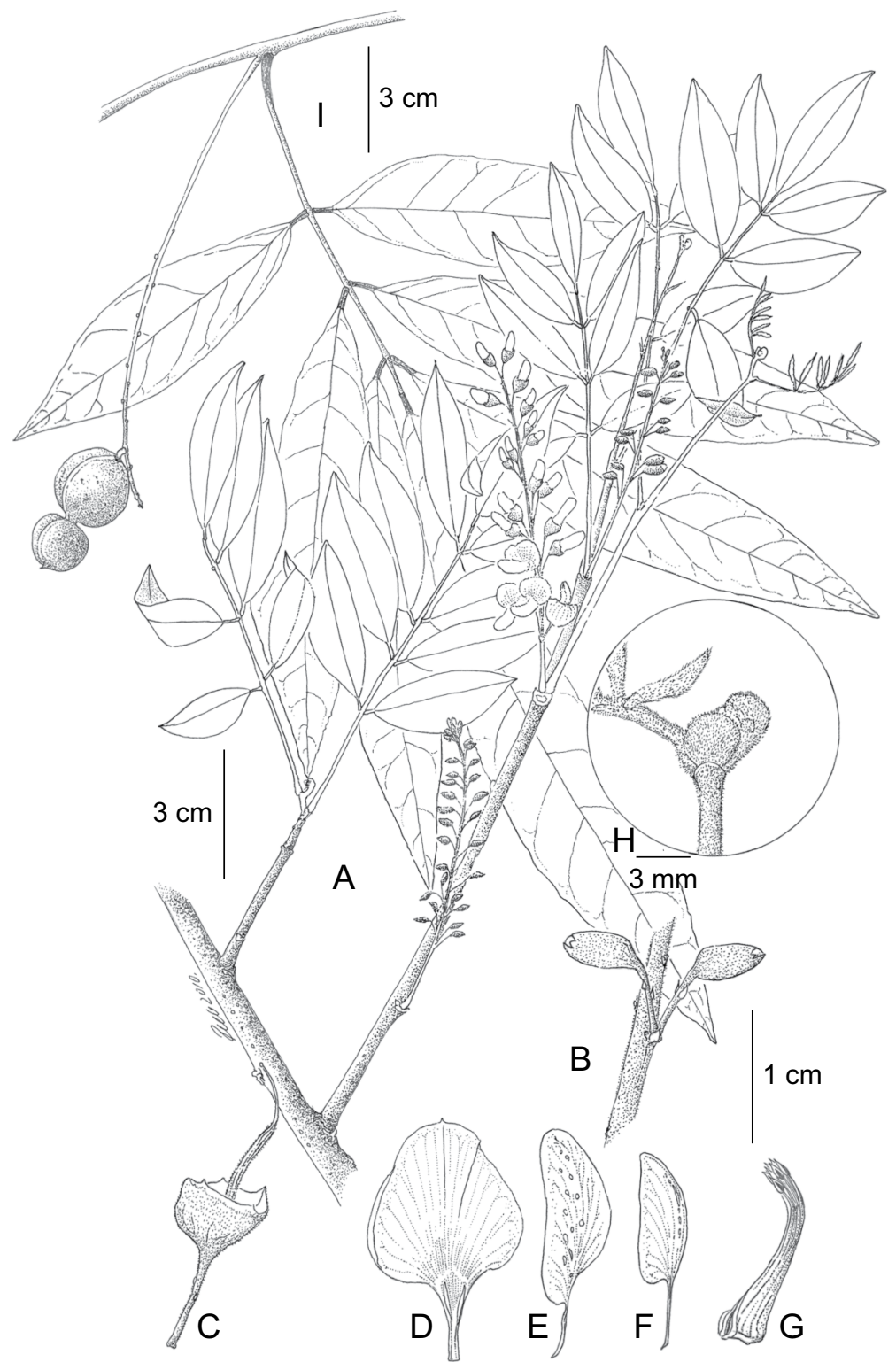

Fig. 3. Muellera chocoensis M. Sousa. A. rama con hojas inmaduras, inflorescencias y flores; B. unidad geminada, mostrando botones florales, bractéolas y bráctea floral; C. cáliz y gineceo; D. estandarte, la cara abaxial; E. ala; F. pétalo de la quilla; G. tubo estaminal; H. yema foliífera mostrando una estípula; I. rama con hojas maduras e infrutescencia. Rama con hojas inmaduras, inflorescencia y flores, tomadas de: E. Forero et al. 4400 (MO); rama con hojas maduras e infrutescencia, tomadas de A. Juncosa 2521 (MEXU). 
largo, axilares, simples, erectas, las flores moderadamente esparcidas a laxas, pedunculadas, el pedúnculo muy breve a 1-1.5 cm de largo; floración generalmente coetánea a tardía; pedúnculos florales muy reducidos o faltantes; pedicelos (5-)7-9 mm de largo, geminados, esbeltos; bractéolas 1.5-2 mm de largo, lanceoladas a algo cocleadas, subopuestas, distantes a la base del cáliz, pronto caducas; cáliz 4-5 $\mathrm{mm}$ de largo, brevemente dentado, giboso en la base vexilar, pardo-amarillento seríceo; hipanto presente; corola violeta, morada, glabra, las nervaduras marcadas, translúcido punteada, (en el ala y la quilla); lámina del estandarte 10-12(-13.5) $\mathrm{mm}$ de ancho, ovada, cuneiforme en la base resolviéndose en la uña, sin aurículas ni callos, con un canalículo vertical bordeado por dos pliegues que se prolongan en la uña; ovario 7-ovulado. Legumbre ca. 4 cm de largo, 1.6-2.2 cm de ancho, subglobosa a cilíndrica cuando con una semilla, moniliforme cuando dos o más semillas, con constricciones muy profundas, cortamente estípidada en la base, redondeada y abruptamente rostrada en el ápice, granulosa y glabra, pardo-amarillenta; semillas no vistas, las maduras reniformes, crasas con la testa quebradiza, el hilo lateral.

Distribución, hábitat, fenología: conocida solamente del área del Chocó y El Valle en la vertiente pacífica de Colombia y en la costa de Ecuador en la Provincia de Esmeraldas. En un hábitat muy limitado en aguas salobres cerca de manglares o en su orilla, ligeramente sobre el límite de la marea alta; en la desembocadura de ríos donde frecuentemente se inunda, en ocasiones sobre playas. Al nivel del mar o a escasos metros 0-5 m de altitud. Sobre suelos lodosos a inundados (acuáticos durante la marea alta). La floración se presenta de principios de febrero a mediados de junio, con un período a principios de septiembre; la fructificación es poco documentada y ocurre a mediados de mayo.

Etimología. El epíteto específico señala al Chocó (Colombia) como el área de distribución más importante de esta especie.

Material adicional examinado: COLOMBIA: Chocó: Quebrada San Pichi, 0605' N, 77¹0' O, C. Barbosa 6497 (MEXU); alrededores de Bahía de Solano, $A$.

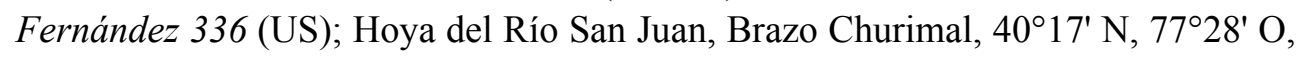
30 Mar. 1979, E. Forero, L.E. Forero y N. Hernández 4400 (MO). El Valle: Baya de Buenaventura, Quebrada de Aguadulce, Costa Pacífica, J. Cuatrecasas 19731 (F); Buenaventura, along bay, E.P. Killip 5236 (US). ECUADOR: Esmeraldas: Limones-Borbón, $5 \mathrm{~km}$ before Borbón, $01^{\circ} 07^{\prime} \mathrm{N}, 79^{\circ} 00^{\prime} \mathrm{O}$, L.B. Holm-Nielsen et al. 26029 (MO). 
5. Muellera crucisrubierae (Pittier) M. Sousa, comb. nov. Basónimo: Lonchocarpus crucisrubierae Pittier, Arb. Arbust. Venez. 6/8: 100. 1927. Tipo: Venezuela. Guárico, llanos de La Ribiera, H. Pittier 12351 (holotipo: US!; isotipo: A!).

6. Muellera denudata (Benth.) M. Sousa, Monogr. Syst. Bot. Missouri Bot. Gard. 45: 1254. 1993. Basónimo: Lonchocarpus denudatus Benth., J. Linn. Soc., Bol. 4 (Suppl.): 95. 1860. Tipo: Brasil. Pará, Rio Tapajoz, Santarem, R. Spruce 595 (holotipo: K!; isotipos: BM!, P!). Derris denudata (Benth.) Ducke, Bol. Tecn. Inst. Agron. N. 18: 196. 1949.

7. Muellera fendleri (Benth.) M.J. Silva et A.M.G. Azevedo, Taxon 61(1): 103. 2012. Basónimo: Lonchocarpus fendleri Benth. J. Linn. Soc., Bol. 4 (Suppl.): 94. 1860. Tipo: Venezuela. Colonia Tobar, A. Fendler 1863 (lectotipo designado por H. Pittier: Trab. Mus. Com.Venez. 4: 234. 1928: K!; isolectotipo GH!).

Hermann (1965) cita para la Flora de Panamá a Lonchocarpus fendleri: (V.C. Dunlap 347, GH!), pero se trata de L. lasiotropis F.J. Herm.

8. Muellera frutescens (Aubl.) Standl., Trop. Woods 34: 41. 1933. Basónimo: Coublandia frutescens Aubl., Hist. Pl. Guiana 2:937, tab. 346. 1775, excl. descr. fl . Tipo: Guayana Francesa. J.B.C.F. Aublet s.n. (holotipo: BM). Fig. 4.

Coronilla monilis L., Pl. Surin.: 13. 1775. Tipo : Surinam. Lectotipo (designado por Geesink en Taxon 33: 743. 1984): Dahlberg 157. Herb . Linn. No 911.1. Lonchocarpus monilis (L.) Az.-Tozzi, Rev. Brasil. Bot. 15(2): 152. 1992. Muellera monilis (L.) M.J. Silva et A.M.G. Azevedo, Taxon 61(1): 103. 2012.

Muellera moniliformis L.f., Suppl. P1. 329, f. 141. 1781 (1782). Tipo: el mismo que el de Coronilla monilis L. Derris moniliformis (L.f.) Ducke, Bol. Técn. Inst. Agron. N. 2: 29. 1944.

Lonchocarpus pallidus Killip, Phytologia 1: 140. 1935. Tipo: Brasil. Maranhão, Rio Maracassumé, Campo do Cabeça, R. de L. Fróes 1882 (holotipo: NY!; isotipos: A!, BM!, G!, K!, P!, US!).

Lonchocarpus pterocarpus sensu Miquel, Linnaea 18: 565, 1844. non DC. Prodr. 2: 260. 1825. Surinam, R.F. Hohenacker 758a (MO!).

Nombres comunes: madre cacao macho, swampy dogwood (Belice).

Arbustos a árboles hasta $7 \mathrm{~m}$ de alto, raíces adventicias presentes; corteza interna sin fluido resinoso al corte; ramas jóvenes pardo-amarillento seríceas, pos- 


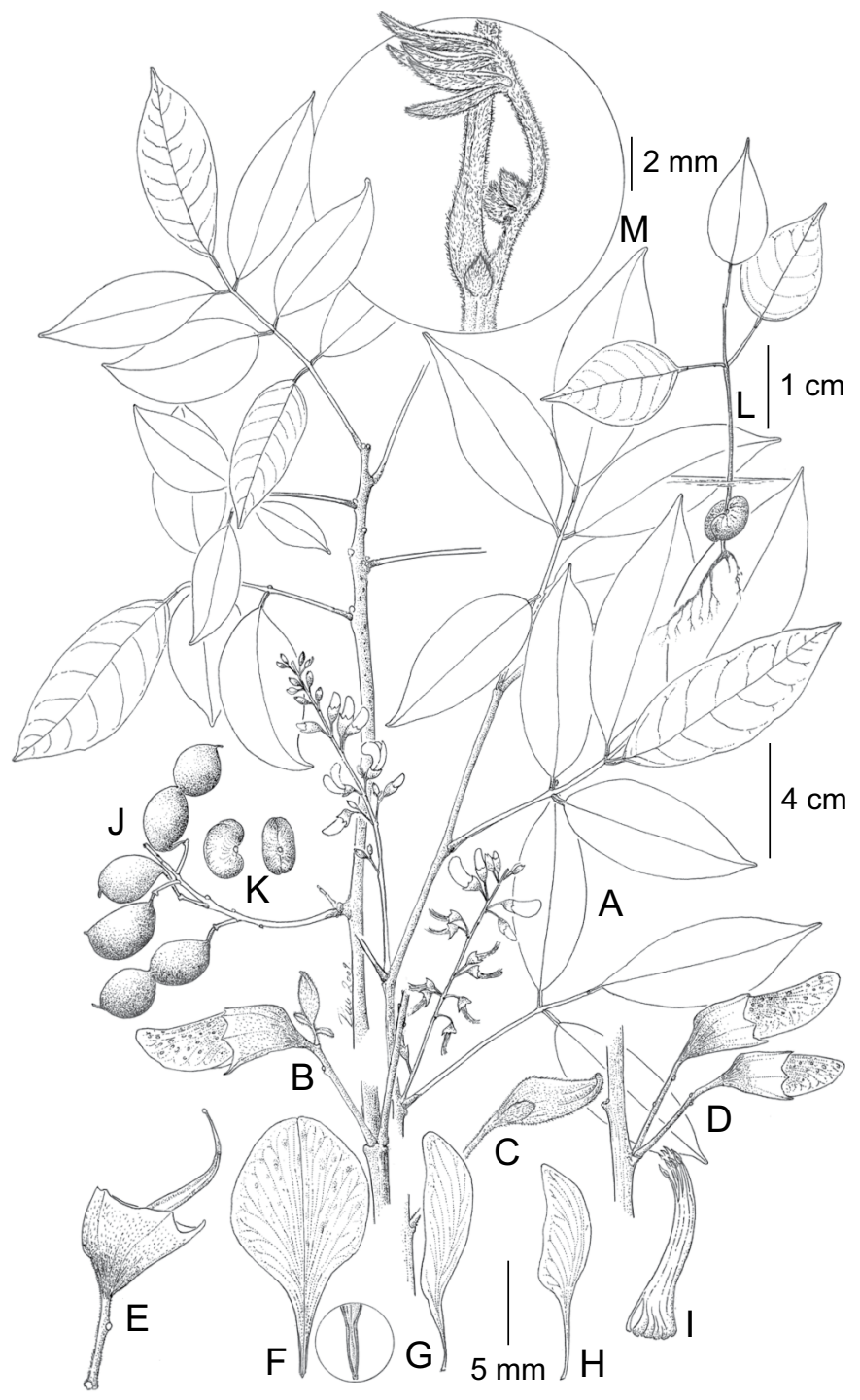

Fig. 4. Muellera frutescens (Aubl.) Standl. A. rama con hojas maduras e inflorescencias; B. unidad geminada, mostrado ramas floríferas (en vez de los pedicelos); C. botón floral mostrando a los dientes del cáliz imbricados con el diente abaxial cubriendo al ápice, una bractéola; D. unidad geminada, mostrando botones florales y cicatrices de bractéolas; E. cáliz y gineceo; F. estandarte cara abaxial, mostrando (en detalle) el canalículo vertical; G. ala; H. pétalo de la quilla; I. tubo estaminal; J. rama con hojas e infrutescenias; K. semillas, cara lateral y dorsal; L. plántula; M. yema foliífera, mostrando una estípula. Rama con hojas, inflorescencias, flores y estípulas, tomadas de $M$. Sousa e I. Calzada 13020 (MEXU); rama con hoja e infrutescencias, tomadas de Menéndez 1152 (MEXU); semillas tomadas de Schipp 642 (HUH); plántula tomada de Menéndez 1152 (MEXU). 
teriormente glabrescentes. Estípulas ca. $3 \mathrm{~mm}$ de largo, ca. $3.2 \mathrm{~mm}$ de ancho, suborbiculares a oblatas, pardo-amarillento seríceas, cubriendo las yemas foliíferas, caducas; pecíolo $2.5-4 \mathrm{~cm}$ de largo, con un canalículo adaxial poco marcado a todo lo largo. Hojas 5(-7)-folioladas; folíolos 5-12 cm de largo, 2-4 cm de ancho, oblongos a ovado-oblongos, marcadamente bicolores, cartáceos a subcoriáceos, diminutamente pelúcido punteados, el ápice acuminado a largamente acuminado a agudo, el haz glabrescente, el envés diminutamente canescente seríceo y densamente papiloso, la nervadura primaria y las secundarias muy poco realzadas en el envés, las nervaduras laterales 6-10 pares. Inflorescencias 2-9 cm de largo, axilares, simples, erectas, las flores, laxas a moderadamente esparcidas en el raquis de la inflorescencia, pedunculadas, el pedúnculo muy breve hasta $1.7 \mathrm{~cm}$ de largo; floración coetánea a tardía; pedúnculos florales muy reducidos o faltantes; pedicelos (4-)6-9 mm largo, geminados, esbeltos; bractéolas 1.6-2 mm de largo, lanceoladas a oblongas, subopuestas a alternas, distantes a la base del cáliz, pronto caducas; cáliz 3.5-5 $\mathrm{mm}$ de largo, giboso en la base vexilar, brevemente dentado con dientes triangular-agudos, esparcidamente pardo-amarillento seríceo, pigmentado, translúcido punteado; hipanto presente; corola rosada, lila, morada, glabra, las nervaduras marcadas, translúcido punteadas; lámina del estandarte 5-9 $\mathrm{mm}$ de ancho, ovada a en ocasiones oblanceolada, cuneiforme en la base resolviéndose en la uña, sin aurículas ni callos, con un canalículo vertical bordeado por dos pliegues prolongándose en la uña; ovario 4-6-ovulado. Legumbres 2-5.5 cm de largo, 1.6-2.8 cm de ancho, subglobosas a cilíndricas cuando con una semilla, en ocasiones con dos, moniliformes cuando 2 o 3 o más semillas, con constricciones muy profundas, sésiles a cortamente estipitadas en la base, redondeadas y abruptamente rostradas en el ápice, lisas a frecuentemente granulosas, glabras, pardoamarillentas; semillas 1-4, 17-18 mm de largo, 12-15 mm de ancho, ca. $6 \mathrm{~mm}$ de grosor, reniformes algo arqueadas, crasas con la testa quebradiza (al secarse se arruga), el hilo lateral. Plántulas con los cotiledones hipogeos; eófilos 1-foliolados, opuestos.

Distribución, hábitat, fenología: se trata de una especie de amplia distribución, sur de México (Veracruz y Tabasco), Centroamérica, Venezuela, Trinidad y Tobago, Guayanas y Norte de Brasil. En un hábitat muy restringido en la desembocadura de ríos y lagunas con presencia de agua salobre. La vegetación en que habitan más frecuentemente son los manglares. En altitudes al nivel del mar. La floración y fructificación se presenta durante casi todo el año. Su dispersión se lleva a cabo por corrientes de agua, al segmentarse el fruto moniliforme en unidades monospermas que flotan en el agua y eventualmente se depositan en playas como en la de Balzapote (Veracruz), estableciéndose en esteros y desembocaduras de ríos. 
Material adicional examinado: MÉXICO: Veracruz: Punta Ostión en la Bahía de Sontecomapan, municipio Catemaco, J.H. Beaman 6479 (MEXU); Punta Levisa, Laguna de Sontecomapan, $R$. Cedillo Trigos 3361 (MEXU); Laguna de Sontecomapan, $6 \mathrm{~km}$ al N del embarcadero, municipio Catemaco, Cedillo 3432 (MEXU); Isla Coscoapan en la Laguna de Sontecomapan, $18^{\circ} 31^{\prime} \mathrm{N}, 95^{\circ} 01^{\prime} \mathrm{O}, F$. Menéndez L. 1152 (MEXU); Rancho Levisa, en la Punta Levisa, orilla norte Laguna Sontecomapan, municipio Catemaco, M. Sousa e I. Calzada 13020 (MEXU). Tabasco: Arroyo Levees, E side Laguna Mechoacan, F.D. Barlow 3/10 (MEXU); Laguna Yucateco, cerca del muelle de Pemex y río Chicozapote, a $10 \mathrm{~km}$ al N de La Venta, municipio Huimanguillo, A. Novelo y V.L. Ramos 1794 (MEXU); Laguna el Yucateco, 18¹1' N, 9401' O, M. Sousa y P. Tenorio L. 13460 (MEXU). GUATEMALA: Escuintla: Inland banks of Canal de Chiquimulilla, between San José and Iztapa, W.E. Harmon 4400 (MO). El Petén: Vaxantum, H.H. Bartlett 12533 (DS). BELICE: Belize: Haulover, C.L. Lundell 6987 (DS). Stann Creek: Mullin River, P.H. Gentle 3394 (A). Toledo: Río Temash, J.D. Dwyer 14773 (MEXU, MO); Jacinto Creek, P.H.

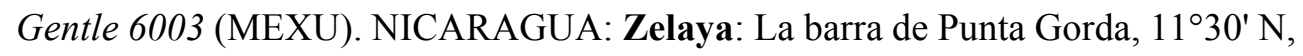
$83^{\circ} 47^{\prime}$ O, P.P. Moreno 13170 (MEXU, MO), between Lamblaya and Laguna Kauropura, P.C. Vincellis 661 (MO). COSTA RICA: [estado no localizado]: Boca de Barranca, J.A. Echeverria 4064 (F). Guanacaste: Parque Nacional Palo Verde, área del Tempisque, $10^{\circ} 16^{\prime} \mathrm{N}, 85^{\circ} 15^{\prime} \mathrm{O}$, U. Chavarria 608, 614 (MEXU). PANAMÁ; Bocas del Toro: vicinity of Chiriquí Lagoon, H. von Wedel 2452 (GH); Darién: Río Congo, South Darien, H. Pittier 6983 (GH); $1 \mathrm{~km}$ E of Santa Fé, E. Tyson et al. 100 (GH). VENEZUELA: Falcón: Río Ricoa, S de Las Dos Bocas, J. Steyermark 113591 (MO); [estado no encontrado]: Orinoco Delta, Cano del Vogre, F.E. Bond et al. 60 (GH); Pedernales, H.M. Curran \& M. Homan 1325 (GH). TRINIDAD Y TOBAGO: Tobago: Smithfield, near Scarborough, W.E. Broadway 4406 (GH). Trinidad: Banks of the Caroni River, Broadway 9193 (A). GUYANA: Northwest: Waini River, Marabo Creek, J.S. de La Cruz 1270 (GH); Kamakusa, upper Mazaruni River 59॰50 ' $\mathrm{O}$, de La Cruz 4093 (GH). SURINAM: [estado no encontrado]: Ajoewa, Rio Courantye, $B W .3090$ (MO). GUAYANA FRANCESA: [estado no encontrado]: vicinity of Cayenne, W.E. Broadway 366 (GH); Demarara-Mohaica Region Georgetown, 650' N, 58 $10^{\prime} \mathrm{O}$, W. Hahn 4808 (MEXU); Essequibo-Isl.-W. Demeran Area, N. and S of Wales, 6²40' N, 58 $11^{\prime}$ O, J.J. Pipoly 9092 (NY). BRASIL: Amazonas: Amapá, Rio Amapá, D.F. Austin et al. 7239 (NY); Maranhão: Maracassumé River Region, R. de L. Fróes 1801 (F, MO).

En ciertas ocasiones, aun en la misma muestra de herbario, además de las flores pediceladas en las unidades geminadas, también se presentan ramas floríferas 
(que remplazan a los pedicelos), donde en el nudo de la bractéola hay un meristemo axilar que produce una flor, véase Fig. 4, B.

9. Muellera lutea (J.R. Johnston) M.J. Silva et A.M.G. Azevedo, Taxon 61(1): 103. 2012. Basónimo: Gliricidia lutea J.R. Johnston, Proc. Amer. Acad. 40(21): 687. 1905. Tipo: Venezuela. Isla Margarita, El Valle, O.O. Miller y J.O. Johnston 246 (sintipo: B, destruido; duplicados: GH!, MO!, P!). Margaritolobium luteum (J.R. Johnston) Harms, Feddes Repert. Nov. Sp. 19: 67. 1923.

10. Muellera lutescens (Pittier) M.J. Silva et A.M.G. Azevedo, Taxon 61(1): 104. 2012. Basónimo Lonchocarpus lutescens Pittier, Arb. Arbust. Venez. 4/5: 59. 1925. Tipo: Venezuela. El Sombrero, H. Pittier 11444 (holotipo: US!; isotipos: K!,NY!).

11. Muellera sericea (Micheli) M.J. Silva et A.M.G. Azevedo, Taxon 61(1): 104. 2012. Basónimo: Bergeronia sericea Micheli, Mém. Soc. Phys. Genève 28:7. 1883. Tipo: Paraguay. Rongement le Rio Paraguay, B. Balansa 1380 (holotipo: G; isotipos: BM!, K!).

12. Muellera tubicalyx (Pittier ex Poppendieck) M.J. Silva et A.M.G. Azevedo, Taxon 61(1): 104. 2012. Basónimo: Lonchocarpus tubicalyx Pittier ex Poppendieck, Novon 2(1): 57. 1992. Tipo: Venezuela. Apure, San Juan de Payara, C.E. Chardon 237 (holotipo: VEN!; isotipo: US!). Fig. 5.

Especie que fue recientemente validada por Poppendieck (1992), y que aquí por primera vez se describe e ilustra al fruto (Fig. 5). Legumbre $4-10.5 \mathrm{~cm}$ de largo, 0.8-1.1 cm de ancho, oblongo-linear a oblonga, indehiscente, algo constricta, aplanada, cinéreo a ferrugíneo velutina, el margen vexilar 2 nervado, 2-2.2 $\mathrm{mm}$ de grosor, con una fisura central a todo lo largo, el margen carinal aquillado, con fisuras dorso-ventrales que se segmentan produciendo unidades monospermas de dispersión. Semillas 2-6, ca. $10 \mathrm{~mm}$ de largo, ca. $5.5 \mathrm{~mm}$ de ancho, ca. $2.1 \mathrm{~mm}$ de grosor, oblongo-reniformes, color castaño.

Material adicional examinado: VENEZUELA: Apure: San Fernando, $H$. Guyon 163 (P). Bolívar: Ciudad Bolivar and vicinity, on the Orinoco river, L.H. Bailey y E. Zoe Bailey 1833 (US). Delta Amacuro (Territorio Federal): Río Manimo, B[V]uelta Triste, Orinoco Delta, F.E. Bond et al. 145 (NY, US). Guárico: departamento Miranda, municipio Calabozo, Río Orituco, sector Puente, A. Castillo S. 419 (VEN); sector Guacharaca, Castillo 487 (VEN). 


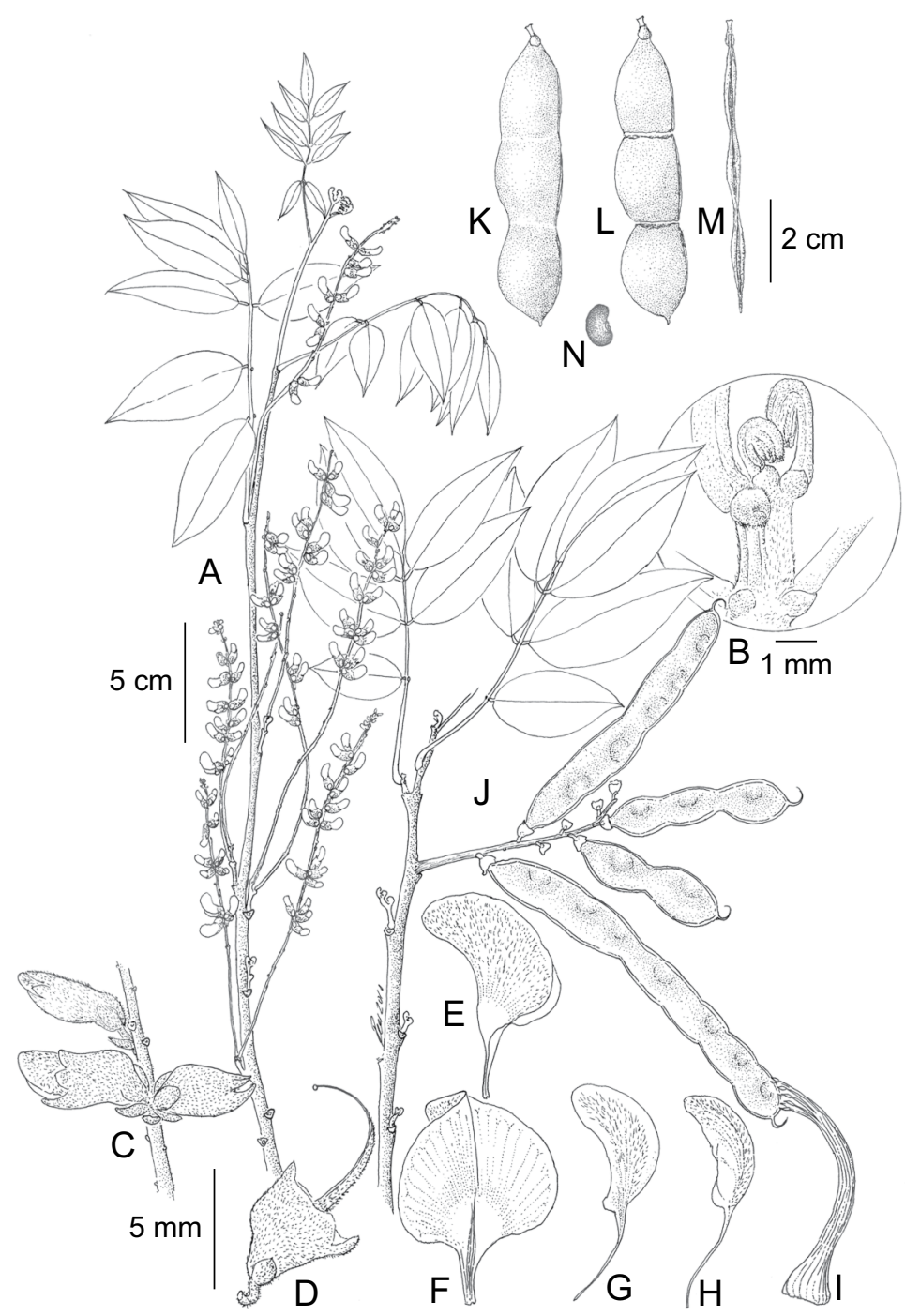

Fig. 5. Muellera tubicalyx (Pittier ex Poppendick) M.J. Silva \& A.M.G. Azevedo . A. rama con hojas e inflorescencias: B. yema folífera, mostrando estípulas; C. unidades geminadas, en las que se muestran las bractéolas y brácteas florales; D. cáliz, mostrando los dientes y el gineceo; estandarte plegado cara adaxial; F. estandarte cara abaxial; G. ala; H. pétalo de la quilla; I. tubo estaminal; J. rama con hojas e infrutescencias; K. legumbre cara valvar; L. legumbre mostrando las fisuras dorso-ventrales; M. legumbre margen vexilar; N. semilla. Rama con hojas inmaduras, inflorescencias y flores, tomadas de H. Guyon 163 (P); estípula, tomada de $A$. Castillo 419 (VEN); rama con hojas maduras e infrutescencias con legumbres inmaduras, tomadas de L.H. Bailey y E. Zoe Bailey 1833 (US): legumbres maduras y semilla, tomadas de Castillo 487 (VEN). 
13. Muellera unifoliolata (Benth.) M. Sousa, comb. nov. Basónimo: Lonchocarpus unifoliolatus Benth., J. Linn. Soc., Bot. 4 (Suppl.): 90. 1860. Tipo: México. Oaxaca, Talea, Sierra San Pedro Nolasco, 1843-44, C. Jürgensen 717 (holotipo: K!; isotipos: G!, MO!). Fig. 6.

Nombres comunes: icaco verde, vainita (Tabasco), rosa morada (Veracruz)

Árboles 3-13 m de alto, perennifolios; ramas glabras. Hojas con arreglo dístico en los brotes nuevos, y posteriormente con arreglo helicoidal por torsión de los tallos en la ramas con hojas maduras; estípulas 1-1.2 mm de largo, angostamente triangulares, erectas, pronto caducas; pecíolo (0.5-)1-2(-3.5) cm de largo, terete a algo angulado, en ocasiones con un canalículo poco marcado adaxialmente; hojas 1-folioladas; folíolo 6-14(-21) cm de largo, 3-6(-11) cm de ancho, con vernación involuta, ovado, oblongo, elíptico a lanceolado, el ápice acuminado a cuspidado, en ocasiones cortamente caudado, lustroso y glabro en la haz y envés, subcoriáceo a membranáceo, epunteado, la nervadura primaria y las secundarias ligeramente realzadas en el envés, nervaduras laterales (4-)5-7 pares. Inflorescencias (3-)6-11(-15) cm de largo, simples, erectas, densifloras en el 1/2 superior del raquis, brevipedunculadas; floración tardía; pedúnculos florales 1-2 mm de largo, la bráctea subyacente persistente; pedicelos 2-2.5 mm de largo; bractéolas 0.7-1.2 mm de largo, lineares a oblongas, algo cóncavas, opuestas a alternas, patentes, cercanas a distantes al cáliz. Flores 8-10 mm de largo; cáliz 2-2.7 $\mathrm{mm}$ de largo, epunteado, moderadamente canescente seríceo con un fondo rojizo, brevidentado, el diente carinal ca. $0.3 \mathrm{~mm}$ de largo, cubriendo al ápice del botón floral, sin giba en la base; corola lila, violeta, morada o guinda, epunteada; lámina del estandarte 5-9 mm de ancho, con mácula blanca a amarillenta, cóncava, obovada, canescente serícea adaxialmente, cuneiforme en la base, sin aurículas, ni callos, resolviéndose en la uña, la uña 1.3-1.9 mm de largo, con un canalículo vertical bordeado por 2 pliegues; tubo estaminal calloso reforzando las dos fenestras basales, las anteras y su conectivo glabros; ovario 2-3-ovulado. Legumbre 4-7.5 cm de largo, 1.9-3 cm de ancho, cortamente falcada, indehiscente, sésil a breviestipitada, rostrada, lateralmente comprimida excepto las valvas ligeramente abombadas a la altura de las semillas, coriácea, glabra, las valvas tenuemente nervadas, el margen vexilar ensanchado con un surco longitudinal, el margen carinal angostamente aquillado; semillas 1-(-2), 14-15 mm de largo, crasas, la testa quebradiza (al secarse) algo arrugada. Plántulas con los cotiledones hipogeos; eófilos opuestos, 1-foliolados.

Distribución, hábitat, fenología: especie endémica a México, en la vertiente del Golfo de México; habita en los estratos arbóreos bajo y mediano en selvas 


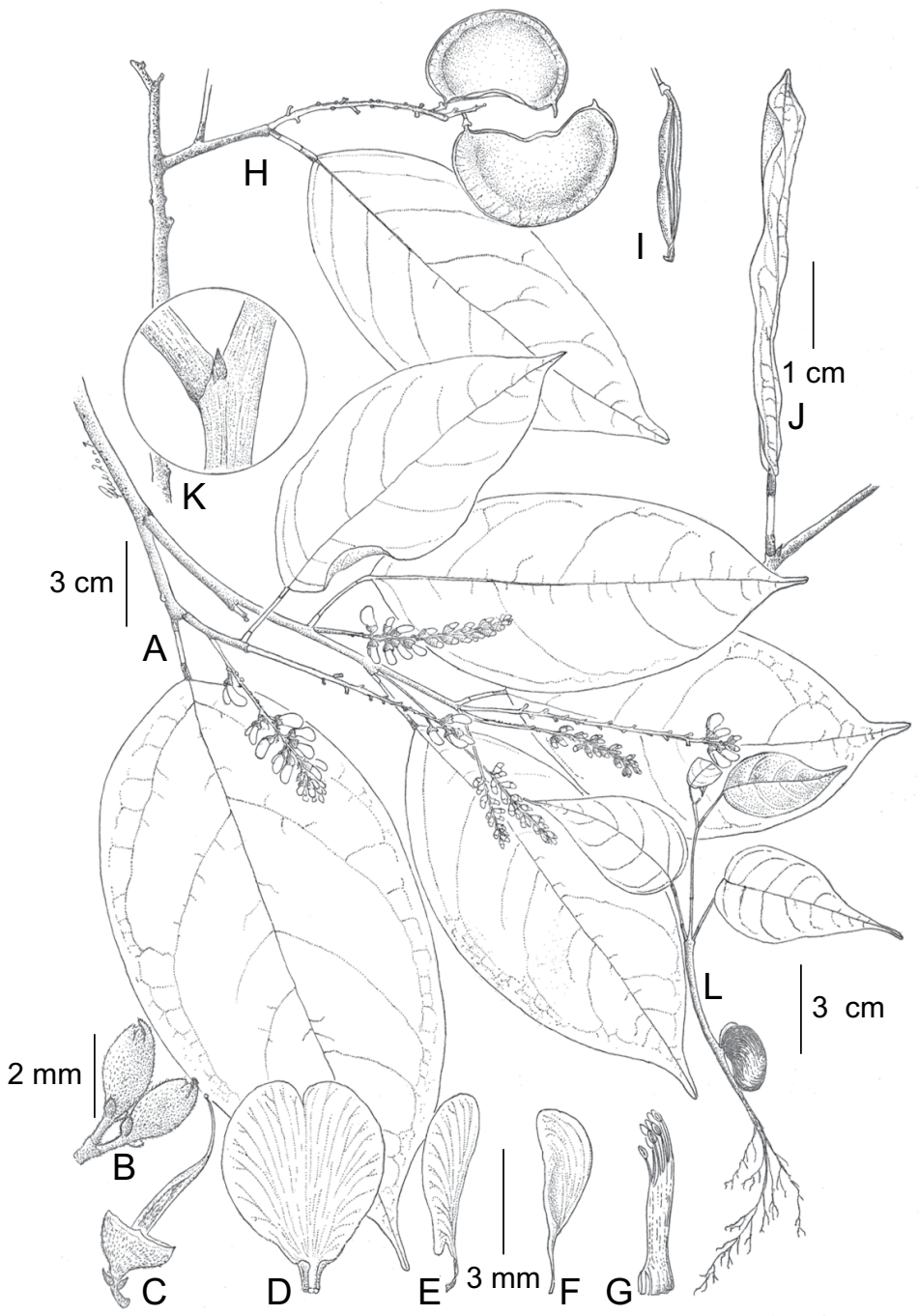

Fig. 6. Muellera unifoliolata (Benth.) M. Sousa. A. rama con hojas e inflorescencia; B. unidad biflora, mostrando botones florales con el diente abaxial cubriendo el ápice, bractéolas, pedicelos y pedúnculo floral; C. cáliz y androceo; D. estandarte cara abaxial; E. ala, F. pétalo de la quilla; G. tubo estaminal; H. rama con hoja e infrutescencia; I. legumbre margen vexilar; J. hoja inmadura, mostrando la vernación involuta; K. estípula; L. plántula. Rama con hojas, inflorescencias y flores, tomadas de T. Wendt el al. 4060 (MEXU); unidad biflora, tomada de $M$. Cházaro 381 (MEXU); rama con hoja, infrutescencia, legumbre margen vexilar, hoja inmadura y estípula, tomadas de $M$. Sousa et al. 13403 (MEXU); plántula, tomada de Sousa 4289 (MEXU). 
altas perennifolias con Dialium, Vatairea, Terminalia, Vochysia, en ocasiones en orilla de cuerpos de agua; también se presenta en selvas bajas perennifolias en cimas montañosas con parteaguas sujetos a fuertes vientos. El clima es (Af) cálido húmedo sin períodos secos; sobre suelos negros arcillosos a rocosos de origen volcánico. En altitudes 20-900 m s.n.m. Con dos períodos de floración, de marzo a finales de julio y de finales de septiembre a mediados de diciembre; fructifica a finales de mayo y posteriormente de finales de agosto a mediados de noviembre.

Material adicional examinado: MÉXICO: Veracruz: Las Cabañas, $5 \mathrm{~km}$ al $\mathrm{N}$ de la desv. de la carr. a El Jicacal, municipio Catemaco, J.I. Calzada 384 (GH, MEXU), 1606 (MEXU); Estación de Biología Tropical, Los Tuxtlas, lote 67, $18^{\circ} 34^{\prime} \mathrm{N}, 95^{\circ} 04^{\prime} \mathrm{O}$, A. Campos V. y J. Ramírez-Amezcua 5989 (MEXU); rivera de la Laguna Escondida, municipio San Andrés Tuxtla, $18^{\circ} 35^{\prime}$ N, 95 $05^{\prime} 23^{\prime \prime}$ O, Campos 6128 (MEXU); cima de El Vigía Estación de Biología Tropical, Los Tuxtlas, $30 \mathrm{~km} \mathrm{~N}$ de Catemaco, municipio San Andrés Tuxtla, R. Cedillo Trigos 2828 (MEXU); Estación de Biología Tropical, Los Tuxtlas, municipio San Andrés Tuxtla, M. Cházaro B. 381 (MEXU); Cerro Vigía, Estación de Biología Tropical, Los Tuxtlas, municipio San Andrés Tuxtla, $18^{\circ} 34^{\prime} \mathrm{N}, 95^{\circ} 04^{\prime} \mathrm{O}$, G. Ibarra M. 2205, 2515 (MEXU); Estación de Biología Tropical, Los Tuxtlas, Ibarra 2179 (MEXU); Barra de Sontecomapan, L. Nevling y A. Gómez-Pompa 147 (MEXU); Playa Escondida, municipio San Andrés Tuxtla, T.P. Ramamoorthy 3503 (MEXU); Playa Escondida, municipio San Andrés Tuxtla, M. Sousa et al. 4064, 4270, 13403 (MEXU); El Vigía, Estación de Biología Tropical, Los Tuxtlas, M. Sousa et al. 4289 (MEXU); El Vigía, lote 67, Estación de Biología Tropical, Los Tuxtlas $18^{\circ} 58^{\prime} \mathrm{N}, 95^{\circ} 08^{\prime}$ O, E. Velasco-Sinaca 652 (MEXU); Arroyo Brasilia cerca del poblado 15 Nuevo, al $\mathrm{N}$ del Río Uxpanapa, $11.5 \mathrm{~km}$ al E de Uxpanapa,

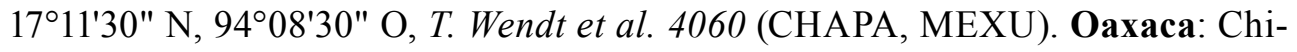
nantla, H. Galeotti 3457 (BR, F, GH, US); San Antonio Nuevo Paraíso, a $500 \mathrm{~m}$

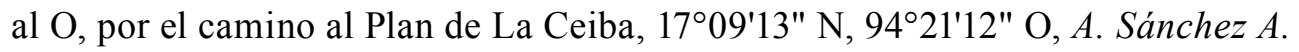
et al. 24 (MEXU). Tabasco: km 59 Huimanguillo a Malpaso, Comisión de Dioscóreas 10894 (MEXU).

Clave de las especies mesoamericanas y del norte de Sudamérica de Muellera

1. Legumbres paucispermas, con 1 o 2(3,4) semillas. 
2. Legumbres glabrescentes a glabras.

3. Legumbres elípticas; flores amarillas; Venezuela 9. M. lutea

3. Legumbres falcadas; flores de otros colores (lila, violeta, morado y blanco), no amarillas.

4. Hojas 1-folioladas; S. México 13. M. unifoliolata

4. Hojas (5-)7-9-folioladas; Venezuela, Guayanas, N. Brasil

5. M. denudata

2. Legumbres pelosas.

5. Flores amarillas; frutos linear-oblongos, con pelosidad canescente; Venezuela 10. M. lutescens

5. Flores violeta a moradas; frutos cortamente oblongos, con pelosidad ferrugínea; Venezuela 4. M. crucisrubieae

1. Legumbres plurispermas, con 5-8 semillas.

6. Legumbres moniliformes o curvadas a espiraladas.

7. Legumbres moniliformes; foliolos 2-4.5(-5.5) $\mathrm{cm}$ de ancho, el envés no rugoso, el ápice acuminado a largamente acuminado; S. México, Centro América, Colombia, Venezuela, Ecuador, Guayanas, N. Brasil.

8. Hojas 5(-7)-folioladas; folíolos 5-12 cm de largo, oblongos a ovadooblongos, las nervaduras laterales 6-10 pares; lámina del estandarte 5-9 $\mathrm{mm}$ de ancho; ovario 4-6-ovulado.

7. M. frutescens

8. Hojas 7-9-folioladas; folíolos (9.5-)11.5-15 cm de largo, lanceolados a angostamente elípticos, las nervaduras laterales 11-13 pares; lámina del estandarte 10-2(-13.5) $\mathrm{mm}$ de ancho; ovario 7-ovulado.

4. M. chocoensis

7. Legumbres aplanadas, curvadas a espiraladas; folíolos 1.1-1.4 cm de ancho, envés rugoso, el ápice obtuso a cortamente acuminado; Ecuador, Paraguay, Argentina 11. M. sericea

6. Legumbres rectas, ni moniliformes, ni curvadas, ni espiraladas.

9. Legumbres 1.1-1.2 cm de ancho.

10. Legumbres glabras; inflorescencia $3.5-7 \mathrm{~cm}$ de largo; pedicelos 3.5-6.5 mm de largo; Colombia 3. M. burkartii

10. Legumbres pelosas; inflorescencia $7.5-11.5 \mathrm{~cm}$ de largo; pedicelos nulos hasta $1.3 \mathrm{~mm}$ de largo; Venezuela 12. M. tubicalyx

9. Legumbres 1.9-2.6 cm de ancho.

11. Foliolos obtusos; legumbres subleñosas con pelosidad ferrugínea; Venezuela 7. M. fendleri 
11. Foliolos acuminados a largamente acuminados; legumbres coriáceas, glabras.

12. Legumbres brillantes, sin moteado; en fruto el pedicelo esbelto hasta $9 \mathrm{~mm}$ de largo, el estípite hasta $10 \mathrm{~mm}$ de largo; Colombia, Grenada, Venezuela

2. M. broadwayi

12. Legumbres opacas con moteado irregular, en fruto el pedicelo algo robusto hasta $4 \mathrm{~mm}$ de largo, el estípite no bien definido; Colombia, Perú, Brasil 1. M. amazonica

\section{DISCUSIÓN}

El género Muellera L.f. (Fabaceae, Millettieae) comprende alrededor de 30 especies de los trópicos de América. En Mesoamérica sólo está representado por dos, de ellas una es endémica a México y la otra de amplia distribución hasta el norte de Brasil; en el norte de Sudamérica (Colombia, Venezuela y Ecuador) con 12 especies; en el sureste de Sudamérica, principalmente Brasil, con alrededor de 18 especies; en las Antillas Menores con sólo una.

El análisis filogenético preliminar generado con secuencias de nrITS (Fig. 7) confirma la idea de que Muellera (14 especies aquí, Cuadro 1) es un grupo monofilético, hermano del género Dahlstedtia con un apoyo bootstrap de $80 \%$. Ambos géneros son grupos hermanos de Lonchocarpus (86\%). Dentro de Muellera los clados que poseen apoyo de ramas mayor de $60 \%$ son el de M. unifoliolata y M. broadwayi (99\%), el de M. cruscisberiae con M. sericea (93\%) y el de M. chocoensis con M. frutescens (67\%). Este último necesita un muestreo mucho mayor para discernir entre taxa supraespecíficos dentro de $M$. frutescens. La nueva especie descrita aquí (M. chocoensis) posee mayor afinidad morfológica y molecular con M. frutescens; ambas comparten el mismo tipo de hábitat y son alopátricas.

\section{AGRADECIMIENTOS}

A Omar González Zorzano por la traducción de las diagnosis al latín y a Fernando Chiang C. por la supervisión de ellas. A Gloria Andrade M., por su constante apoyo en la organización del texto y la información requerida. A Ramiro Cruz por sus inmejorables ilustraciones botánicas. Por proporcionar, en visitas o préstamos, el material para este trabajo, a los curadores de los siguientes herbarios: A, BM, BR, 
CHAPA, DS, DUKE, F, G, GH, K, MEXU, MO, NY, P, TEX-LL, US, VEN, VT, quienes facilitaron su consulta. También contamos con la valiosa asesoría de Teresa Terrazas en la interpretación anatómica. Agradecemos la ayuda técnica de Laura Márquez (secuenciador IBUNAM). El trabajo molecular fue posible gracias al apoyo parcial de UNAM-DGAPA, PAPIIT IN222109.

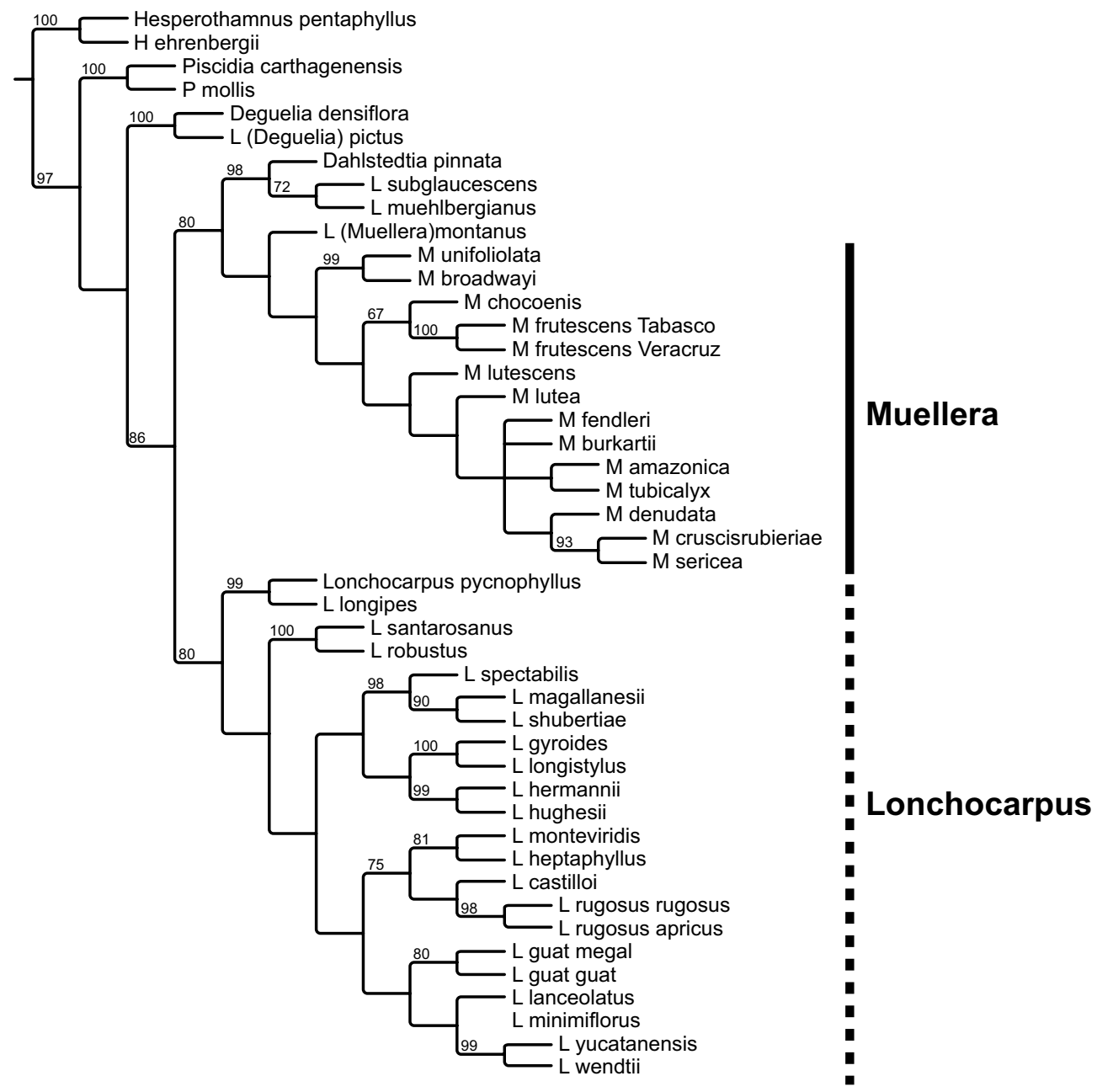

Fig. 7. Árbol de consenso estricto para Muellera y géneros hermanos. Sobre las ramas valores de bootstrap superiores a $60 \%$. 
Cuadro 1. Lista de especies y ejemplares utilizados en el análisis filogenético preliminar de Muellera.

\begin{tabular}{|c|c|c|}
\hline Especie & Colector & Localidad \\
\hline Dahlstedtia pinnata & HC. De Lima 4/1 & Brasil \\
\hline Deguelia densiflora & B. Hamel 19661 & Costa Rica \\
\hline Hesperothamnus ehrenbergii & E. Guízar 5187 & México, Hidalgo \\
\hline H. pentaphyllus & P. Tenorio 20102 & México, Puebla \\
\hline Lonchocarpus castilloi & D. Álvarez 6121 & México, Campeche \\
\hline L. guatemalensis var. guatemalensis & G. Aguilar 521 & México, Chiapas \\
\hline L. guatemalensis var. megalanthus & P. Tenorio 19026 & México, Sinaloa \\
\hline L. gyroides & R. Cruz D. 4789 & México, Guerrero \\
\hline L. heptaphyllus & T. Croat 13923 & Panamá \\
\hline L. hermannii & $\mathrm{Hu} \mathrm{L} 13$ & México, Sonora \\
\hline L. hughesii & Hughes, 1718 & Honduras \\
\hline L. lanceolatus & Hughes 1723 & México, Oaxaca \\
\hline L. longistylus & E. Martínez 31964 & México, Campeche \\
\hline L. longipes & B. Peguero y A. Veloz 526 & República Dominicana \\
\hline L. (Deguelia) pictus & R. Pursell 8629 & Venezuela \\
\hline L. magallanesii & A. Solís M. 366 & México, Jalisco \\
\hline L. minimiflorus & Hughes 1223 & Guatemala \\
\hline L. monteviridis & Haber 770 & Costa Rica \\
\hline L. muehlbergianus & Tressens et al. 1992 & Argentina \\
\hline L. pycnophyllus & S. A. Thomson 7445 & República Dominicana \\
\hline L. robustus & A. Campos 6212 & México, Veracruz \\
\hline L. rugosus subsp. apricus & M. Lavin 8204 & México, Chiapas \\
\hline L. rugosus subsp. rugosus & E. Martínez 35467 & México, Campeche \\
\hline L. santarosanus & Hughes 1229 & El Salvador \\
\hline L. schubertiae & M. Martínez 84 & México, Guerrero \\
\hline L. spectabilis & E. Hernández XA3 & México, Guerrero \\
\hline L. subglaucescens & Hatschbach 41090 & Brasil \\
\hline L. wendtii & Brigada Vázquez 363 & México, Veracruz \\
\hline L. yucatanensis & E. Martínez 37214 & México, Campeche \\
\hline Muellera amazonica & Amaral et al. 360 & Brasil \\
\hline M. broadwayi & L. Cárdenas 4104 & Venezuela \\
\hline M. burkartii & Callejas et al. 4340 & Colombia \\
\hline M. chocoensis & E. Forero y R. Jaramillo 4400 & Colombia \\
\hline
\end{tabular}


Cuadro 1. Continuación.

\begin{tabular}{lll}
\hline Especie & Colector & Localidad \\
\hline $\begin{array}{l}\text { M. crucisrubierae } \\
\text { M. denudata }\end{array}$ & F. Tamayo 4062 & Venezuela \\
M. fendleri & G. Davidse 14802 & Venezuela \\
M. frutescens & N. Ramírez 3103 & Venezuela \\
M. frutescens & A. Novelo 2105 & México, Tabasco \\
M. lutea & M. Sousa 13020 & México, Veracruz \\
M. lutescens & Curian 1200 & Venezuela \\
Lonchocarpus (Muellera) montanus & Pereira 3296 & Venezuela \\
M. sericea & A. Krapovickas 45636 & Brasil \\
M. tubicalyx & F. E. Bond 145 & Paraguay \\
M. unifoliolata & G. Ibarra 3376 & Venezuela \\
Piscidia carthagenensis & J. Rivera 2252 & México, Veracruz \\
Piscidia mollis & Hu 1117 & México, Oaxaca \\
\hline
\end{tabular}

\section{LITERATURA CITADA}

Bentham, G. 1860. Synopsis of Dalbergieae, a tribe of Leguminosae. J. Linn. Soc. Bot. 4 (Supplement): pp. 1-128.

Burkart, A. 1952. Las leguminosas argentinas, silvestres y cultivadas. 2a. ed. Acme. Buenos Aires. pp. 1-579.

Burkart, A. 1969. Leguminosas nuevas o críticas, VII. Darwiniana 15(3-4): 501-549.

Geesink, R. 1984. Scala Millettieaerum. A survey of the genera of the tribe Millettieae (Leguminosae-Papilionoideae), with methodological considerations. Leiden Botanical Series 8. E.J. Brill/Leiden University Press. Leiden, Netherlands. pp. 1-131.

Hermann, F. J. 1965. 10. Lonchocarpus H.B.K. Flora of Panama (Family 83. Leguminosae) Ann. Missouri Bot. Gard. 52(1): 39-47.

Linné, f., Carl von. 1781 [1782]. Suppl. P1.: 53, 329.

Silva, M. J. \& A. M. G. A. Tozzi. 2008. Four new Brazilian species of Lonchocarpus Kunth (Leguminosae, Papilionoideae, Millettieae). Brittonia 60(4): 318-328.

Silva, M. J., A. M. G. A. Tozzi \& G. P. Lewis. 2010. Two new species of Lonchocarpus (Leguminosae, Papilionoideae, Millettieae) from Brazil. Kew Bull. 65(1): 29-35.

Silva, M. J., L. Paganucci de Queiroz, A. M. Goulart de Acevedo Tozzi, G. P. Lewis y A. Pereira de Sousa. 2012. Phylogeny and biogeography of Lonchocarpus sensu lato and its allies in the tribe Millettieae (Leguminosae, Papilionoideae). Taxon 61(1): 93-108. 
Sousa S., M. \& M. Peña de Sousa. 1981. New World Lonchocarpinae. In: Polhill, R. M. \& P. B. Raven (eds.). Advances in Legume Systematics, Part 1. Royal Bot. Gard. Kew, England. pp. 261-281.

Sousa S., M. 1993. Muellera denudata (Benth.) M. Sousa. Monogr. Syst. Bot. Mo. Bot. Gard. 45: 1254.

Sousa S., M. 2005. Las especies del género Lonchocarpus (Leguminosae, Papilionoideae: Millettieae) para Bolivia. Novon 15: 590-598.

Sousa S., M. 2009. La sect. Punctati del género Lonchocarpus (Leguminosae, Papilionoideae, Millettieae) para Mesoamérica. Novon 19: 239-255.

Teixeira, S. de P., M. de Castro \& A. M. G. de Tozzi. 2000. Secretory cavities and pellucid dots in leaflets of Lonchocarpus (Leguminosae, Papilionoideae, Millettieae). Pl. Syst. Evol. 221: 66-68 